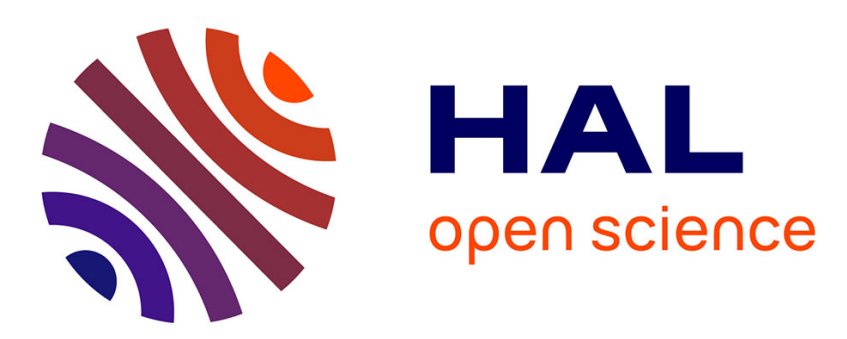

\title{
Novel multi-scale parallel mini-channel contactor for monodisperse water-in-oil emulsification
}

\author{
Peipei Zhou, Dominique Tarlet, Min Wei, Yilin Fan, Lingai Luo
}

\section{To cite this version:}

Peipei Zhou, Dominique Tarlet, Min Wei, Yilin Fan, Lingai Luo. Novel multi-scale parallel minichannel contactor for monodisperse water-in-oil emulsification. Chemical Engineering Research and Design, 2017, 121, pp.233-244. 10.1016/j.cherd.2017.03.010 . hal-03146394

\author{
HAL Id: hal-03146394 \\ https://hal.science/hal-03146394
}

Submitted on 19 Feb 2021

HAL is a multi-disciplinary open access archive for the deposit and dissemination of scientific research documents, whether they are published or not. The documents may come from teaching and research institutions in France or abroad, or from public or private research centers.
L'archive ouverte pluridisciplinaire HAL, est destinée au dépôt et à la diffusion de documents scientifiques de niveau recherche, publiés ou non, émanant des établissements d'enseignement et de recherche français ou étrangers, des laboratoires publics ou privés. 
archives-ouvertes

\title{
Novel multi-scale parallel mini-channel contactor for monodisperse water-in-oil emulsification
}

\author{
Peipei Zhou, Dominique Tarlet, Min Wei, Yilin Fan, Lingai Luo
}

\section{To cite this version:}

Peipei Zhou, Dominique Tarlet, Min Wei, Yilin Fan, Lingai Luo. Novel multi-scale parallel minichannel contactor for monodisperse water-in-oil emulsification. Chemical Engineering Research and Design, Elsevier, 2017, 121, pp.233-244. 10.1016/j.cherd.2017.03.010 . hal-03146394

\section{HAL Id: hal-03146394 \\ https://hal.archives-ouvertes.fr/hal-03146394}

Submitted on 19 Feb 2021

HAL is a multi-disciplinary open access archive for the deposit and dissemination of scientific research documents, whether they are published or not. The documents may come from teaching and research institutions in France or abroad, or from public or private research centers.
L'archive ouverte pluridisciplinaire HAL, est destinée au dépôt et à la diffusion de documents scientifiques de niveau recherche, publiés ou non, émanant des établissements d'enseignement et de recherche français ou étrangers, des laboratoires publics ou privés. 
Dear author,

Please note that changes made in the online proofing system will be added to the article before publication but are not reflected in this PDF.

We also ask that this file not be used for submitting corrections. 


\title{
Novel multi-scale parallel mini-channel contactor for monodisperse water-in-oil emulsification
}

\author{
${ }_{1}$ Peipei Zhou ${ }^{a, b}$, Dominique Tarlet $^{a, *}$, Min Wei ${ }^{a}$, Yilin Fan ${ }^{a}$, Lingai Luo ${ }^{a}$ \\ ${ }^{a}$ Laboratoire de Thermique et Énergie de Nantes (LTEN) CNRS UMR 6607 Université de Nantes, Rue Christian Pauc, \\ BP 50609, 44306 Nantes Cedex 3, France \\ b School of Mechanical and Automotive Engineering, South China University of Technology (SCUT), Guangzhou, \\ China
}

A R T I C L E I N F O

\section{Article history:}

Received 4 November 2016

Received in revised form 17

February 2017

Accepted 10 March 2017

Available online $\mathrm{xxx}$

Keywords:

Water-in-oil emulsification

Parallel minichannel contactor

Multi-scale tree-like distributor

Physical properties

Coefficient of variation

\begin{abstract}
A B S T R A C T
This paper presents the development of a novel parallel minichannel contactor for monodisperse water-in-oil emulsification. The novel contactor having 16 Y-junctions in parallel equipped with multi-scale tree-like fluid distributor and collector was realized and experimentally tested. Oils with different physical properties and water were used as continuous phase and dispersed phase, respectively. Influences of different factors including the parallelization, the water/oil flow-rate ratio and two-phase physical properties on the two-phase flow characteristics and on the coefficient of variation were studied and discussed. Results showed that for water-pure oil flow, the novel parallel minichannel contactor is capable of producing monodisperse water-in-oil emulsions with high throughput and low energy consumption under our tested conditions. The Ohnesorge number $(\mathrm{Oh})$ has a significant influence on the emulsion monodispersity and the capillary number (Ca) appears as a proper indicator for liquid-liquid break-up regimes. A predictive correlation for the Oh number was proposed by fitting the experimental data obtained in the study.
\end{abstract}

\section{Introduction}

Microfluidic devices have recently received great attentions in the field of emulsification process because of the ability to generate uniform-sized droplets and plugs, also known as monodisperse emulsion. As an important step to produce micromaterials (e.g., microparticles and microcapsules), monodisperse emulsions are intensively required in numerous applications such as microreaction synthesis (Meng et al., 2015), drug delivery (Duncanson et al., 2012) and the production of colloid particles (Jeong et al., 2012).

Many researchers studied systematically the emulsification phenomena in a single micro-channel, including the formation of droplets (Link et al., 2004), the size distribution (Gunther and Jensen, 2006) and the influence of physical properties on emulsion dispersity (Nisisako and Torii, 2008).
Various configurations for liquid-liquid contact have been investigated, including T-junction (Xu et al., 2006), Y-junction (Steegmans et al., 2009) and flow-focusing (Liu et al., 2007). The results reported in the literature show that the single microchannel can generally provide good emulsion monodispersity, especially with the help of some delicate adjustments in the flow-rates or channel configuration (e.g. Sugiura et al., 2002; Link et al., 2004; Utada et al., 2005; Priest et al., 2006; Belkadi et al., 2015). However, the relative low throughput of single micro-channel is an identified barrier that hinders its development for industrial-scale mass production.

The parallelization of minichannels is a feasible scheme to generate monodisperse emulsion with a high throughput. Table 1 summarizes various studies in the literature on emulsification process with parallel channels. It is generally reported that the microchannels array effectively augments

\footnotetext{
* Corresponding author.

E-mail address: dominique.tarlet@univ-nantes.fr (D. Tarlet).
} 


\begin{tabular}{|c|c|}
\hline \multicolumn{2}{|c|}{ Nomenclature } \\
\hline $\mathrm{Ca}$ & Capillary number (-) \\
\hline$D_{w}$ & average diameter $(\mathrm{mm})$ \\
\hline$E$ & energy dissipation rate $\left(\mathrm{J} \mathrm{kg}^{-1}\right)$ \\
\hline I & range for average value $(-)$ \\
\hline$J_{0}$ & oil superficial velocity $\left(\mathrm{m} \mathrm{s}^{-1}\right)$ \\
\hline$J_{w}$ & water superficial velocity $\left(\mathrm{m} \mathrm{s}^{-1}\right)$ \\
\hline$n$ & number of droplets (-) \\
\hline $\mathrm{Oh}$ & Ohnesorge number (-) \\
\hline$P$ & injection pressure $(\mathrm{Pa})$ \\
\hline$P_{w}$ & coefficient of variation (\%) \\
\hline$Q$ & volume flow rate $\left(\mathrm{mL} \mathrm{min}^{-1}\right)\left(\mathrm{m}^{3} \mathrm{~s}^{-1}\right)$ \\
\hline $\operatorname{Re}$ & Reynolds number (-) \\
\hline S & section area $\left(\mathrm{m}^{2}\right)$ \\
\hline$u(-)$ & normal law (-) \\
\hline $\mathrm{W}, \mathrm{Z}$ & channel width (m) \\
\hline \multicolumn{2}{|c|}{ Greek symbols } \\
\hline$\alpha_{r}$ & assumed risk (\%) \\
\hline$\delta$ & dimensionless parameter (-) \\
\hline$\epsilon$ & dimensionless parameter $(-)$ \\
\hline$\gamma$ & superficial tension $\left(\mathrm{mN} \mathrm{m}^{-1}\right)$ \\
\hline$\mu$ & dynamic viscosity (Pa s) \\
\hline$\rho$ & density $\left(\mathrm{kg} \mathrm{m}^{-3}\right)$ \\
\hline$\sigma_{w}$ & standard deviation of sample (-) \\
\hline \multicolumn{2}{|c|}{ Subscripts } \\
\hline e & emulsion (-) \\
\hline 0 & oil $(-)$ \\
\hline$w$ & water (-) \\
\hline$w / 0$ & interface (-) \\
\hline
\end{tabular}

investigations (Luo et al., 2007; Fan et al., 2008) confirmed that the multi-scale tree-like distributor could provide better flow distribution uniformity preferentially for laminar flow, which usually fits the working condition for emulsification process. This promising concept has been widely applied in thermal, fluidic and reactive devices (Luo et al., 2007) such as liquid-liquid mixers (Fan et al., 2010; Tondeur et al., 2011), heat exchangers (Fan et al., 2008; Luo et al., 2007, 2008), gas-liquid contactors (Yue et al., 2010), multifunctional reactors (Guo et al., 2013, 2014), etc.

In this study, we try to apply the multi-scale tree-like design for the water-oil two-phase emulsification, in order to obtain monodisperse emulsion with high productivity and low energy consumption. For this purpose, a novel parallel mini-channel contactor having 16 Y-junctions equipped with multi-scale tree-like distributor/collector was developed and experimentally tested. To further investigate the local twophase flow patterns at the junction, a single Y-junction replica was also fabricated and tested for comparison.

In the rest of this paper, we shall first introduce the experimental set-up used in this study. Then the multi-scale network with 16 parallel mini-channels and the single Y-junction replica will be described in detail. After that, the flow patterns in the single Y-junction mini-channel replica will be discussed. Then the water-oil emulsification in the multi-scale contactor will be systemically studied, including the influence of different factors (parallelization, the physical properties and flow rates) on the emulsification and its coefficient of variation. The energy dissipation rate will also be calculated and compared to that of other emulsification devices reported in the literature. A predictive correlation based on non-dimensional groups will be proposed by fitting the experimental data. Finally, main conclusions and future perspectives will be summarized.

\section{Methodologies}

\subsection{Experimental test-rig}

As schematically shown in Fig. 1, the experimental setup consists of test channels, oil and water circuits and the data acquisition system. Water was fed in the channel by a FRESENIUS Injectomat Agilia syringe pusher, with $3 \%$ uncertainty on the water flow-rate. Pressurized air (1.6-3.0 bar) regulator and needle valve were used to control the flow rate of oil (less than $5 \%$ variation within 5 minutes). To visualize and record the two-phase flow patterns in minichannels, a fast CCD camera LAVision HighSpeed Star 6 equipped with the macro objective was used. The focus was made in the channel depth. Background illumination was provided by a $50 \mathrm{~W}$ halogen spot located in the line of sight, right above the transparent test section.

\subsection{Test section}

Fig. 2a shows the designed parallel minichannel contactor which is composed of three parts: multi-scale tree-like fluid distributor for oil and for water respectively, 16 Y-junctions for water-oil contact and multi-scale tree-like collector for emulsion collection. The tree-like fluid distributor has four bifurcating generations $\left(2^{4}=16\right)$, connecting single inlet port to 16 end-ports. Its detailed geometric dimensions are listed in Table 2. under certain constraints, such as minimal viscous dissipation and constant void volume. Numerical and experimental 
Table 1 - Selected literature on droplet formation and emulsion coefficient of variation within single or parallel micro-channels.

\begin{tabular}{|c|c|c|c|}
\hline Authors & Liquid-liquid & Experimental devices & Key findings \\
\hline Tice et al. (2004) & Non-viscous & $\begin{array}{l}\text { Single T-junction } \\
50 \mu \mathrm{m} \times 50 \mu \mathrm{m}\end{array}$ & $\begin{array}{l}\text { The big difference in viscosities enhance } \\
\text { mixing. When } \mathrm{C} a \text { is low, interfacial } \\
\text { tension dominates to produce sharp } \\
\text { plugs. }\end{array}$ \\
\hline Garstecki et al. (2006) & Water-Oil & $\begin{array}{l}\text { Single T-junction } \\
100 \mu \mathrm{m} \times 33 \mu \mathrm{m}\end{array}$ & $\begin{array}{l}\text { Re } \ll 1, \mathrm{Ca}<0.01 \text {, Eq. }(5) \text { can be used } \\
\text { to predict the plug length. }\end{array}$ \\
\hline Steegmans et al. (2009) & $\begin{array}{l}\text { Milli-Q-Water } \\
\text { Ethanol-Water }\end{array}$ & $\begin{array}{l}\text { Single Y-junction } \\
23 \mu \mathrm{m} \times 5 \mu \mathrm{m}\end{array}$ & $\begin{array}{l}\text { Droplet size in Y-junction is mainly determined } \\
\text { by } \mathrm{Ca} \text { of the continuous phase. }\end{array}$ \\
\hline Link et al. (2004) & Plug emulsions & $\begin{array}{l}\text { A series of three } \\
\text { T-junctions satisfying } \\
\frac{l_{0}}{\pi w_{0}}>1 \\
\text { (lo plug length, } \\
w_{0}: \text { channel width.) }\end{array}$ & $\begin{array}{l}\text { Sequential passive break-up to make up smaller } \\
\text { droplets with low coefficient of variation }(<3 \%) \text {. }\end{array}$ \\
\hline Li et al. (2008) & $\begin{array}{l}\text { Deionized } \\
\text { Water-Oil }\end{array}$ & $\begin{array}{l}\text { Four parallel flow- } \\
\text { focusing devices }\end{array}$ & $\begin{array}{l}\text { The device produces monodisperse } \\
\text { emulsions }(<4 \%) \text { and the droplet size increases with } \\
\text { the wider orifices. }\end{array}$ \\
\hline Kobayashi et al. (2007) & Oil-Water & $\begin{array}{l}\text { Array } 1500 \text { channels } \\
22.5 \mathrm{~mm} \times 8 \mathrm{~mm}\end{array}$ & $\begin{array}{l}\text { Minimum coefficient of variation }(\mathrm{CV}) \simeq 9 \% \text {; } \\
\text { droplet production rates is high, reaching up to } \\
2.4 \times 10^{4} \text { droplets per second. }\end{array}$ \\
\hline Nisisako and Torii (2008) & Water-Oil & $\begin{array}{l}\text { A glass chip with } \\
128 \text { cross-junctions } \\
\text { or co-flow geometries } \\
(42 \mathrm{~mm} \times 42 \mathrm{~mm})\end{array}$ & $\begin{array}{l}\text { The cross-junction model and } \\
\text { co-flowing model produce } 320 \mathrm{ml} / \mathrm{h} \text { emulsions } \\
\text { with low coefficient of variation of } 1.3 \% \text { and } \\
3.3 \% \text {, respectively. }\end{array}$ \\
\hline Kashid et al. (2010) & $\begin{array}{l}\text { Kerosene-Acetic } \\
\text { Acid-Water }\end{array}$ & $\begin{array}{l}\text { Numbering-up of six } \\
120^{\circ} \text { Y-shape mixing } \\
\text { elements. }\end{array}$ & $\begin{array}{l}\text { Influence of interfacial tension on } \\
\text { the mass transfer performance. }\end{array}$ \\
\hline Nisisako et al. (2012) & Oil-Water & $\begin{array}{l}\text { Chip with circularly } \\
\text { parallelized } \\
\text { droplet generator. }\end{array}$ & $\begin{array}{l}\text { High production of emulsions } \\
\text { and low coefficient of variation } \\
\text { in single or compound emulsions. }\end{array}$ \\
\hline
\end{tabular}

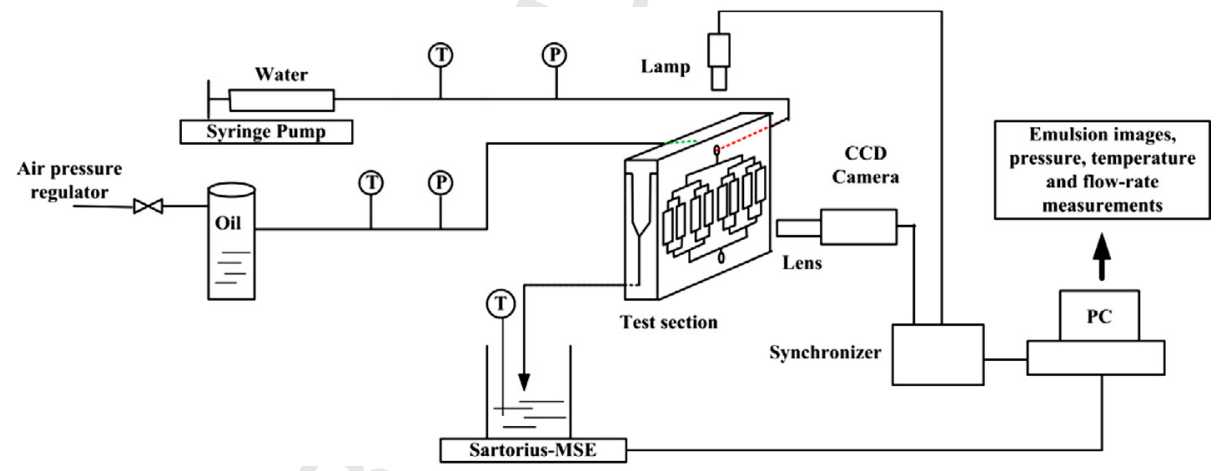

Fig. 1 - Schematic of the experimental apparatus for the measurement of two-phase flow pattern in a single minichannel and in a parallel minichannel contactor.

It obeys the scaling relation that accounts for both the fluid equidistribution among the end-ports and the minimized pressure drop (Tondeur et al., 2009). Through their proper fluid distributor, the introduced oil and water flows are divided into 16 sub-streams each, which are then guided into the Yjunctions to produce emulsions. The $16 \mathrm{Y}$-junctions are spaced
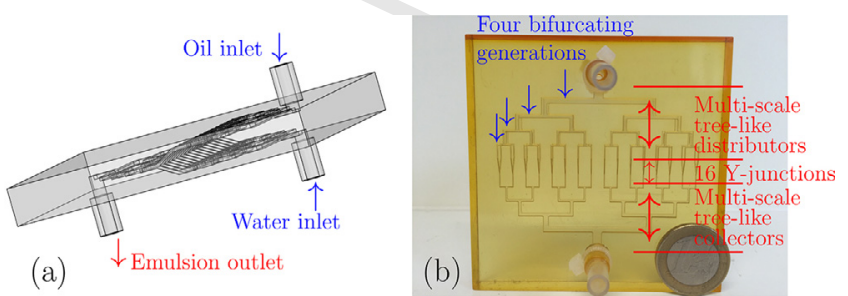

Fig. 2 - Parallel minichannel contactor for water-in-oil emulsification. (a) side view; (b) photography (front view oil and water inlets are at the top) next to a $1 €$ coin.
$4 \mathrm{~mm}$ between the axis of one junction and another. In more detail, each Y-junction has a rectangular cross-section (Fig. 3a) of $1.0 \mathrm{~mm}$ in width and $0.6 \mathrm{~mm}$ in depth, with a contact angle of $60^{\circ}$ (shown in Fig. 3b). The endpoints of the $16 \mathrm{Y}$ junctions are connected to the fluid collector which has the same geometry as the distributor. Using this split-contactrecombine technique, the parallel minichannel contactor is expected to produce high throughput of water-in-oil emulsion

Table 2 - Dimensions of the multi-scale tree-like fluid distributor / collector.

\begin{tabular}{cccc}
$\begin{array}{c}\text { Bifurcating } \\
\text { generation }\end{array}$ & $\begin{array}{c}\text { Channel length } \\
(\mathrm{mm})\end{array}$ & $\begin{array}{c}\text { Channel width } \\
(\mathrm{mm})\end{array}$ & $\begin{array}{c}\text { Channel depth } \\
(\mathrm{mm})\end{array}$ \\
\hline 1 & 16 & 2.1 & 1 \\
2 & 8 & 1.35 & 1 \\
3 & 4 & 1 & 1 \\
4 & 2 & 0.6 & 1 \\
\hline
\end{tabular}




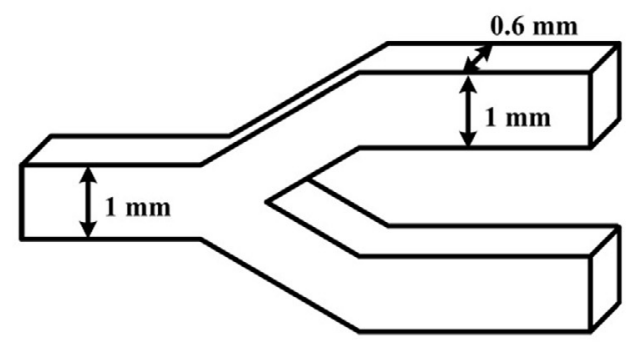

(a)

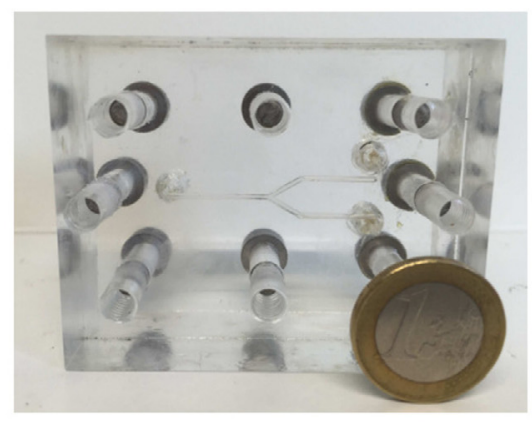

(b)

Fig. 3 - Single Y-junction replica. (a) Schematic view; (b) Photography next to a $1 €$ coin.

(compared to that in single minichannel) with low coefficient of variation.

The smallest channel dimensions of the present device are $600 \mu \mathrm{m}$ in depth and $1 \mathrm{~mm}$ in width, resulting in a hydraulic diameter of $750 \mu \mathrm{m}$. Considering the larger channel sizes in the distributor/collector (Table 2), they are called minichannels rather than microchannels (Kandlikar and Grande, 2003; Zhao and Middelberg, 2011). Generally, two-phase flows are confined in small channels whose hydraulic diameter is smaller than the capillary length (Aarts, 2005) so that interfacial tension dominates (de Gennes et al., 2005).

The integral contactor prototype (Fig. 2b) was fabricated with transparent resin (WaterClear Ultra 10122) using laser stereolithography. In this process, photopolymer is cured selectively at the local focus of ultraviolet laser. With post processing, the quality of final product (surface planarity) is guaranteed.

A single Y-junction replica (shown in Fig. 3) is also constructed to investigate the local two-phase flow patterns at the junction, where the oil and water meet. It was fabricated in-house, using the milling technique in two PMMA rectangular blocks: one with milled Y-junction, the other one being a cover. They were stuck against each other using screws, and tested without leakage. The measurements of droplet shape/size and emulsion coefficient of variation in this single Y-junction replica under different tested conditions will provide a reference case (ideal condition) for the comparison with those in the parallel minichannel contactor.

Wettability properties are tested by measuring the contact angle of a sessile drop on both PMMA and photopolymer surfaces. They are found to be similar. The average roughness of the PMMA surface mechanically etched is less than $1 \mu \mathrm{m}$ (Belkadi et al., 2015) whereas the maximum roughness of the photopolymer surface is estimated to be about $10 \mu \mathrm{m}$ (Campbell et al., 2002).

\subsection{Working fluids}

Tap water (Nantes métropole) and filtered sunflower oil (Carrefour) were used as working fluids. In order to modify the interfacial tension and viscosity of the two-phase fluid, additives of Butanol (Sigma-Aldrich) and SPAN83 (sorbitan sesquioleate, Fisher Scientific) were used. The chosen SPAN83 mass percentage is up to $0.4 \mathrm{wt}$. $\%$ since its critical micellar concentration (CMC) is from 0.8 to $1.0 \mathrm{wt}$ \% (Belkadi et al., 2015). Using these products and formulation, the obtained water-oil dispersion was observed to be stable for more than 50 minutes with a small diameter $(5-10 \mu \mathrm{m})$ (Tarlet et al., 2014). Stability remains significant with more than about 10 minutes in the present experiments, at a larger mean diameter around $1 \mathrm{~mm}$. Thus, it can still be considered as an emulsion in the present work. Table 3 lists the physical properties of working fluids measured between $22^{\circ} \mathrm{C}$ and $25^{\circ} \mathrm{C}$.

\subsection{Parameters measurement and uncertainty analysis}

Interfacial tension $\gamma_{w / 0}$ and viscosity $\mu$ were measured using a KRÜSS K-12 tensiometer and a LAMY RM-200 rheometer with their uncertainty of $5 \%$ and $1 \%$, respectively. Water flow-rate $\mathrm{Q}_{w}$ was controlled by the syringe pump (0-2 $\left.\mathrm{ml} / \mathrm{min}\right)$, with $3 \%$ uncertainty of the full scale. Oil flow-rate $Q_{0}$ was measured by means of weighing scales of Sartorius-MSE ( $1 \mathrm{~Hz}$ sampling, accuracy of $0.001 \mathrm{~g}$ ). Concerning oil flow rate, the uncertainty is $5 \%$ within a time scale of $5 \mathrm{~min}$ for each measurement. Inlet pressures of water and oil were measured by using compact pressure transmitters of Gems 3100 series (0-2.5 bar with an uncertainty of $0.25 \%$ of the full scale). The pressure at the outlet of the test section was atmosphere pressure. K-type thermocouples were used to measure the fluid temperature at different locations (see Fig. 1). Details about the instruments and their measuring ranges and precisions are presented in Table 4.

Different parameters and dimensionless numbers are then introduced to describe the characteristics of water-in-oil emulsions produced both in single Y-junction and in parallel minichannel contactor. The coefficient of variation $P_{w}$ of the obtained emulsions is defined in Eq. (1). It is also called the polydispersity of emulsions (Link et al., 2004). $P_{w}$ is the standard deviation $\sigma_{w}$ divided by their mean diameter $D_{w}$ of more than 15 water droplets in single Y-junction, or more than 100 water droplets in the outcoming area of parallel minichannel contactor (as shown in red frame in Fig. 12).

$P_{w}=\frac{\sigma_{w}}{D_{w}}$

The sampling size (15 and 100) is determined based on Eq. (2), where $\sigma_{w}$ is the standard deviation (of water droplets diameters), $D_{w}$ is the mean diameter and $I$ is the reliable range for the mean diameter ( $I=2.5 \%$ in this study). With a low level of assumed risk $\alpha_{r}=1 \%$, the normal law gives $u(0.995)=2.58$. As a result, the minimum sampling size $n_{\min }$ calculated is always smaller than 100 . Thus, the present average diameters $D_{w}$ are based on samples of 100 droplets as it was done in Li et al. (2008). In this study, the mean diameter $D_{w}$ of water droplets were obtained statistically by using image processing software Image-Pro Plus 7.0. The image resolution rate was set as 30 pixels per millimeter, which gives an 
Table 3 - Physical properties of the used fluids.

\begin{tabular}{|c|c|c|c|c|c|c|}
\hline \multirow[t]{2}{*}{ Liquids - temperature } & \multirow[t]{2}{*}{ Water } & \multirow[t]{2}{*}{ Pure oil } & \multicolumn{2}{|c|}{ Butanol (wt.\%) } & \multicolumn{2}{|c|}{ SPAN (wt.\%) } \\
\hline & & & 5 & 13 & 0.3 & 0.4 \\
\hline$\gamma[\mathrm{mN} / \mathrm{m}]-25^{\circ} \mathrm{C}$ & 73.5 & 33.7 & - & - & - & - \\
\hline$\gamma_{w / 0}[\mathrm{mN} / \mathrm{m}]-25^{\circ} \mathrm{C}$ & - & 27.6 & 12.8 & 5.4 & 11.3 & 10.4 \\
\hline$\mu[\mathrm{mPa} \mathrm{s}]-22^{\circ} \mathrm{C}$ & 0.96 & 58 & 44 & 34 & 58 & 58 \\
\hline$\rho[\mathrm{g} / \mathrm{L}]-25^{\circ} \mathrm{C}$ & 998 & 865 & 862 & 857 & 865 & 865 \\
\hline Supplier & Tap water & Carrefour & \multicolumn{2}{|c|}{ Sigma-Aldrich } & \multicolumn{2}{|c|}{ Fisher Scientific } \\
\hline
\end{tabular}

Table 4 - Range and precision of experimental instruments.

\begin{tabular}{|c|c|c|c|c|}
\hline Parameter & Device & Range & Unit & Precision \\
\hline Water flow rate & Syringe pump & {$[0,2]$} & $\mathrm{ml} / \mathrm{min}$ & $1 \%$ \\
\hline Oil flow rate & Sartorius-MSE 2203 & {$[0,1000]$} & $\mathrm{g} / \mathrm{s}$ & $5 \%$ \\
\hline Working temperature & K-type thermocouple & {$[-75,250]$} & ${ }^{\circ} \mathrm{C}$ & $0.1^{\circ} \mathrm{C}$ \\
\hline Pressure transmitters & Gems 3100 Series & {$[0,2.5]$} & bar & $0.25 \%$ \\
\hline Viscosity & LAMY RM-200 rheometer & - & $\mu \mathrm{PaS}$ & $1 \%$ \\
\hline Surface tension & KRÜSS tensiometer & - & $\mathrm{mN} / \mathrm{m}$ & $5 \%$ \\
\hline Camera & LAVision HighSpeed Star 6 & - & - & - \\
\hline$P_{w}=\frac{\sigma_{w}}{D_{w}}$ & Image-Pro Plus 7.0 & - & - & - \\
\hline
\end{tabular}

estimated uncertainty of $6.7 \%$ considering 2 pixels of maximum uncertainty. For some non-spherical droplets, the equivalent diameter was measured that corresponds to the diameter of a sphere with the same projected area as the droplet.

$c=\frac{\sigma_{w}}{D_{w}} \Rightarrow n_{\min }=\frac{c u\left(1-\alpha_{r} / 2\right)}{I}$

Dimensionless numbers such as capillary number $(\mathrm{Ca})$ and Ohnesorge number $(\mathrm{Oh})$ are also introduced for describing the liquid-liquid two-phase flow. Ca number is widely known as the criterion to discern among different break-up regimes in the liquid-liquid flows (Zhao and Middelberg, 2011). It compares the viscous shear stress within the continuous phase to the interfacial tension, as defined in Eq. (3) where $J_{0}$ is the superficial velocity of the continuous phase.

$\mathrm{Ca}=\frac{J_{0} \mu_{0}}{\gamma_{w / 0}}$

Meanwhile, the Oh number relates the viscous force to the inertial and interfacial tension force of the dispersed phase (Belkadi et al., 2015), as defined in Eq. (4).

$\mathrm{Oh}=\frac{\mu_{\mathrm{o}}}{\left(\rho_{w} D_{w} \gamma_{w / 0}\right)^{0.5}}$

For convenience of comparison, all the tests were carried out between $21.3^{\circ} \mathrm{C}$ and $22.9^{\circ} \mathrm{C}$ to avoid big variation of fluid physical properties with temperature. Viscosity $\mu$ is measured at $22^{\circ} \mathrm{C}$ to better fit the temperature range of the experiments. The values of density $\rho$ and interfacial tension $\gamma_{w / 0}$ are measured at $25^{\circ} \mathrm{C}$ since they do not significantly vary over this range of temperature.

For each measurement, the two-phase flow was stable over more than 5 minutes and good reproducibility was observed. The capillary number (Ca) varies between 0.004 and 0.08 , the Reynolds number (Re) between 0.0033 and 0.45 , and the Ohnesorge number $(\mathrm{Oh})$ between 0.3 and 0.7 under the tested conditions (cf. Table 5).

In the present work, the uncertainty analysis for the derived quantities was performed following the method of
Moffat (1988). The calculation indicates the maximum uncertainty of $11 \%$ for superficial velocities $J_{o}$ and $J_{w}, 12 \%$ for the capillary number $(\mathrm{Ca}), 4.3 \%$ for the Ohnesorge number $(\mathrm{Oh})$ and $20 \%$ for the total energy dissipation rate $(E)$. It should be claimed here that these estimations are conservative because most uncertainties between channels generated by imperfections and irregularities in fabrication were considered to be $50 \mu \mathrm{m}$ for channel size in the parallel minichannel contactor.

\section{Flow patterns in a single Y-junction minichannel replica}

The hydrodynamic characteristics of the water-oil flow have been investigated in the single Y-junction minichannel replica. Typical liquid-liquid flow patterns such as droplet flow or plug flow are generally reported in the existing literature. Fig. 4 shows the observed flow patterns in the present Y-junction. Characterization of the observed flow patterns is discussed as follows.

In minichannel, droplet flow is characterized by water droplets dispersed in the continuous oil phase, of which the shape is close to spherical with a diameter smaller than or close to the width of the channel. Plug flow is characterized by elongated water plug with axial length clearly larger than

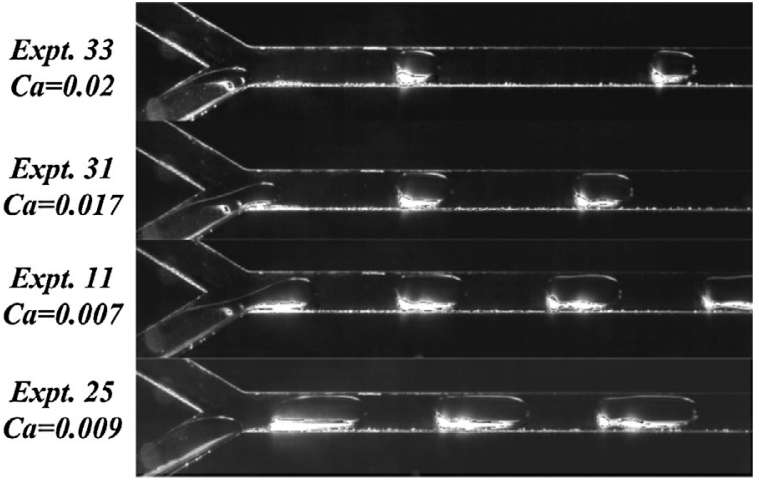

Fig. 4 - Photographies of the oil-water two-phase flow in the single Y-junction minichannel replica. 
Table 5 - Results of emulsification in the parallel minichannel contactor. $\boldsymbol{n}$ is the number of droplets in the red appointed area in Fig. 12. As an indicator, $P_{w-S}$ is the coefficient of variation of emulsion measured in the individual Y-junction

replica under the same working conditions.

\begin{tabular}{|c|c|c|c|c|c|c|c|c|c|}
\hline $\mathrm{Q}_{w}$ & $m L \cdot \min ^{-1} Q_{0}$ & $\begin{array}{c}P_{\text {water }} \\
\text { bar }\end{array}$ & $\begin{array}{l}P_{0} \\
\text { bar }\end{array}$ & $n$ & $\mathrm{Ca}$ & $\mathrm{Oh}$ & $\begin{array}{l}D_{w} \\
m m\end{array}$ & $\begin{array}{c}P_{w} \\
\%\end{array}$ & $\begin{array}{r}P_{w-s} \\
\%\end{array}$ \\
\hline \multicolumn{10}{|c|}{ Pure oil, $\mu_{0}=58 \mathrm{mPa} . \mathrm{s}, \gamma_{w / 0}=27.6 \mathrm{mN} . \mathrm{m}^{-1}$} \\
\hline 1 & 2.05 & 1.24 & 1.19 & 35 & 0.0074 & 0.33 & 1.07 & 4.48 & 1.36 \\
\hline 0.7 & 2.62 & 1.15 & 1.17 & 28 & 0.0096 & 0.36 & 0.97 & 4.42 & 1.35 \\
\hline 0.7 & 2.9 & 1.2 & 1.2 & 30 & 0.011 & 0.36 & 0.99 & 3.04 & 1.25 \\
\hline 1.35 & 2.56 & 1.3 & 1.2 & 43 & 0.0093 & 0.34 & 1.04 & 4.53 & 2.14 \\
\hline 1 & 2.15 & 1.24 & 1.2 & 37 & 0.0079 & 0.34 & 1.05 & 5.39 & 2.51 \\
\hline 0.7 & 2.47 & 1.2 & 1.19 & 32 & 0.009 & 0.37 & 0.89 & 4.32 & 1.53 \\
\hline 0.4 & 1.1 & 1.08 & 1.03 & 23 & 0.004 & 0.33 & 1.09 & 4.59 & 2.18 \\
\hline 1.35 & 2.88 & 1.24 & 1.28 & 42 & 0.011 & 0.37 & 0.89 & 4.29 & 1.51 \\
\hline 0.4 & 2.84 & 1.16 & 1.21 & 20 & 0.01 & 0.38 & 0.86 & 5.81 & 2 \\
\hline \multicolumn{10}{|c|}{$0.3 \%$ SPAN, $\mu_{0}=58 \mathrm{mPa} . \mathrm{s}, \gamma_{w / 0}=11.7 \mathrm{mN} . \mathrm{m}^{-1}$} \\
\hline 1 & 2.84 & 1.2 & 1.25 & 40 & 0.024 & 0.59 & 0.844 & 8.02 & 2.76 \\
\hline 1 & 2.29 & 1.21 & 1.19 & 42 & 0.02 & 0.58 & 0.86 & 7.65 & 2.31 \\
\hline 1 & 3.35 & 1.23 & 1.27 & 40 & 0.03 & 0.58 & 0.864 & 8.4 & 3.1 \\
\hline 1 & 4.02 & 1.24 & 1.33 & 41 & 0.034 & 0.59 & 0.83 & 8.9 & 2.56 \\
\hline 0.7 & 2.18 & 1.2 & 1.15 & 36 & 0.019 & 0.54 & 0.96 & 8.65 & 3.1 \\
\hline \multicolumn{10}{|c|}{$0.4 \%$ SPAN, $\mu_{0}=58 \mathrm{mPa} . \mathrm{s}, \gamma_{w / 0}=10.4 \mathrm{mN} . \mathrm{m}^{-1}$} \\
\hline 1 & 3.45 & 1.21 & 1.29 & 40 & 0.033 & 0.62 & 0.83 & 8.52 & 3.92 \\
\hline 1 & 5.04 & 1.32 & 1.38 & 48 & 0.049 & 0.66 & 0.75 & 9.99 & 5.88 \\
\hline 1 & 2.35 & 1.18 & 1.2 & 42 & 0.023 & 0.62 & 0.85 & 7.94 & 4.2 \\
\hline \multicolumn{10}{|c|}{$5 \%$ Butanol, $\mu_{0}=44 \mathrm{mPa} . \mathrm{s}, \gamma_{w / 0}=12.8 \mathrm{mN} . \mathrm{m}^{-1}$} \\
\hline 0.4 & 2.95 & 1.15 & 1.12 & 20 & 0.018 & 0.4 & 0.91 & 3.41 & 1.9 \\
\hline 0.7 & 2.76 & 1.17 & 1.15 & 36 & 0.016 & 0.38 & 1.05 & 4.95 & 1.57 \\
\hline 0.7 & 3.1 & 1.17 & 1.14 & 35 & 0.019 & 0.39 & 1.01 & 3.81 & 1.2 \\
\hline 1 & 2.91 & 1.2 & 1.18 & 47 & 0.017 & 0.38 & 1.04 & 4.25 & 1.32 \\
\hline 1 & 2.3 & 1.17 & 1.14 & 45 & 0.014 & 0.36 & 1.16 & 4.56 & 1.24 \\
\hline 1 & 4.28 & 1.18 & 1.3 & 60 & 0.025 & 0.39 & 0.96 & 4.49 & 2.26 \\
\hline 1.35 & 3.41 & 1.21 & 1.28 & 75 & 0.021 & 0.38 & 1.04 & 6.44 & 2.12 \\
\hline 0.7 & 4.44 & 1.17 & 1.29 & 35 & 0.026 & 0.41 & 0.87 & 3.05 & 1 \\
\hline 0.4 & 3.74 & 1.18 & 1.24 & 22 & 0.022 & 0.44 & 0.81 & 5 & 2 \\
\hline 1 & 2.68 & 1.18 & 1.15 & 47 & 0.016 & 0.36 & 1.14 & 3.96 & 1.05 \\
\hline 0.4 & 2.7 & 1.12 & 1.13 & 22 & 0.016 & 0.38 & 1.07 & 4.4 & 2.02 \\
\hline 1.35 & 3.03 & 1.23 & 1.25 & 49 & 0.019 & 0.38 & 1.06 & 5.54 & 1.95 \\
\hline \multicolumn{10}{|c|}{$13 \%$ Butanol, $\mu_{o}=34 \mathrm{mPa} . \mathrm{s}, \gamma_{w / 0}=5.4 \mathrm{mN} . \mathrm{m}^{-1}$} \\
\hline 1 & 3.26 & 1.13 & 1.1 & 53 & 0.036 & 0.51 & 0.81 & 11.98 & 9.16 \\
\hline 1 & 2.94 & 1.1 & 1.1 & 50 & 0.032 & 0.51 & 0.817 & 11.4 & 5.27 \\
\hline
\end{tabular}

the channel diameter and separated by the oil plugs in the axial direction, and usually the lengths of water and oil plugs are constant. The pictures of Expts. 11, 25 and 31 in Fig. 4 show plugs with their length more than $20 \%$ longer than the channel width. Consequently, they belong to the characteristic plug flow regime. Photography of Expt. 33 in Fig. 4 shows the droplets having their size $+/-15 \%$ close to the channel width. However it is not strictly droplet flow since the water droplets are not really spherical because of the rectangular cross-section of the mini-channel. We call them "apparent droplet flow" as being a transitional pattern between the characterized droplet flow (not observed in the current study) and the characteristic plug flow. The characteristic droplet flow pattern as reported in the literature is not observed under the tested conditions of this study.

Fig. 5 shows the two-phase flow regime map for the single Y-junction replica as a function of oil and water superficial velocities. Two groups can be seen: experiments 1 to 14 use pure oil, and experiments 15 to 35 use oil with 5\% Butanol. The transition line concerns the cases with $5 \%$ Butanol. The cases with pure oil are different due to a significant difference in viscosity and interfacial tension (see Table 3). The transition line from droplet flow to plug flow proposed by Kim et al.
(2014), and the transition from apparent droplet flow to characterized plug flow are both indicated in Fig. 5 for comparison. It may be observed that most of the present liquid-liquid flows belong to the plug flow regime, according to Kim et al. (2014). However, this criterion can be discussed mainly because of two reasons. Firstly, the break-up of the dispersed phase is based on a Y-junction here, instead of a T-junction by Kim et al. (2014). Secondly, the dimensions of the channel with rectangular cross-section and the two-phase flow conditions are not exactly the same.

It is further observed that there is a critical value of $\mathrm{Ca}$ number that distinguishes different break-up mechanisms of droplet/slug formation. This critical value is typically reported equal to 0.01 in the literature (Zhao and Middelberg, 2011). When $C a \leq 0.01$, the interfacial tension force is stronger than the viscous shear stress. It is known as the squeezing regime, as explained by Garstecki et al., 2006 that proposed the mechanism of squeeze stage and growth stage for the formation of final plug in a T-junction minichannel. At first, the dispersed phase enters and fills the main channel. In this stage, the plug length is $L_{1}=\varepsilon z$, where $z$ is the width of the main channel and $\varepsilon$ is usually equal to 1 . Then the plug neck with characteristic width $d$ decreases at a rate equal to 


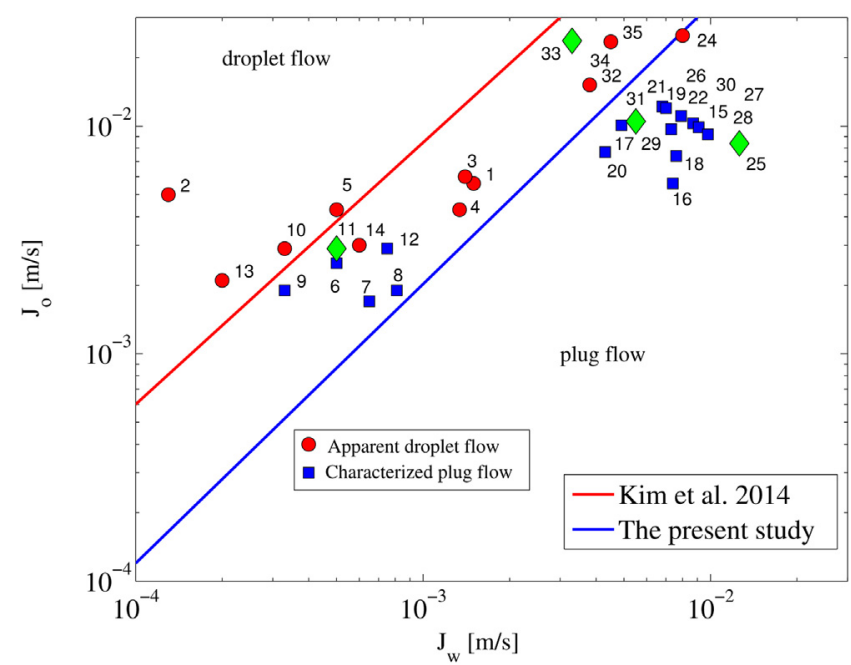

Fig. 5 - Emulsion flow patterns in the single Y-type micro-channel replica, as a function of oil and water superficial velocities. Photographies of Expts. 11, 25, 31 and 33 (green spots) are shown in Fig. 4.
$348 \quad \frac{L}{\mathrm{z}}=\delta \frac{\mathrm{Q}_{w}}{\mathrm{Q}_{0}}+\varepsilon$ the superficial velocity of continuous phase, $u_{\text {squeeze }} \approx J_{0}=\frac{\mathrm{Q}_{0}}{\mathrm{~S}}$. During the time for the neck disappearing, the plug elongates at a rate $u_{\text {growth }} \approx J_{w}=\frac{\mathrm{Q}_{w}}{\mathrm{~S}}$, so the final length of the plug is $L \approx L_{1}+d \frac{u_{\text {growth }}}{u_{\text {squeeze }}}=\varepsilon z+d \frac{\mathrm{Q}_{w}}{\mathrm{Q}_{0}}$. Finally the correlation (Garstecki et al. (2006)) to predict the length of plugs is:

where $\delta$ is a dimensionless parameter in relation to the minichannel geometry and dimensions.

In this study, we found that this mechanism proposed for T-junction (Garstecki et al., 2006) is logically applicable to Yjunction minichannel. Figure 6 shows the experimental data obtained in this study and the fitting curves using the correlation of Garstecki et al. (2006) (Eq. (5)). The experimental data of Garstecki et al. (2006) and Xu et al. (2008) for rectangular T-junction microdevices are also introduced for comparison. It can be observed that the predicting results $(\delta=2, \varepsilon=1$ for the current study) fit well the experimental data, with $9.7 \%$ of mean absolute percentage error (MAPE) concerning the squeezing regime $(\mathrm{C} a<0.01)$. MAPE is a parameter defined in

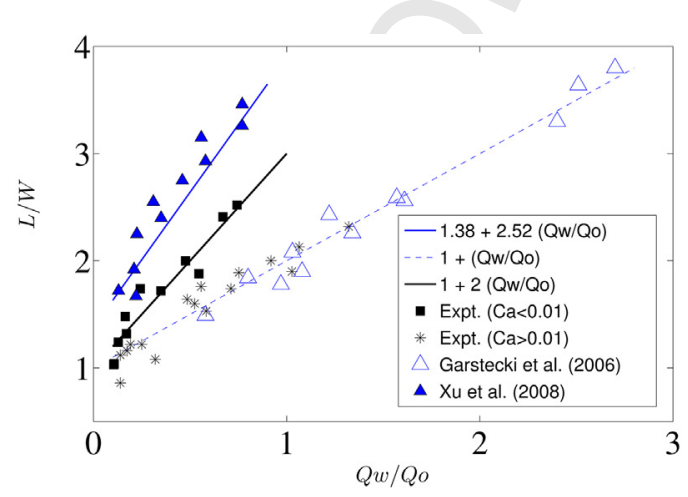

Fig. 6 - Experimental data and fitting curves for the length of plugs. Current study: Y-junction $\left(60^{\circ}\right), 1000 \mu \mathrm{m} \times 600 \mu \mathrm{m}$; Garstecki et al., 2006: T-junction, $100 \mu \mathrm{m} \times 33 \mu \mathrm{m}$; Xu et al., 2008: T-junction, $200 \mu \mathrm{m} \times 150 \mu \mathrm{m}$.

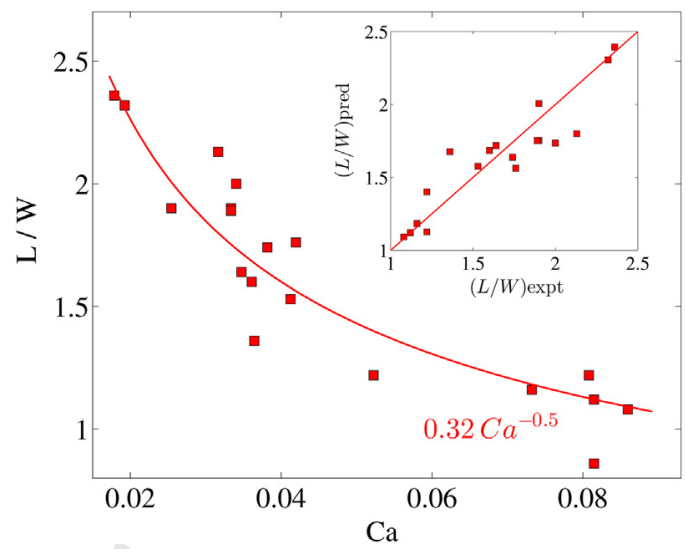

Fig. 7 - Experimental data and fitting curve for the length of plugs for $\mathrm{C} a>0.01$.

Eq. (6) which is often used to estimate the deviation between the measured $\left(M_{i}\right)$ and predicted values $\left(P_{i}\right)$ (Kim et al., 2014).

$\operatorname{MAPE}(\%)=\frac{1}{N} \sum_{i=1}^{n}\left|100 \times \frac{M_{i}-P_{i}}{M_{i}}\right|$

Fig. 6 also shows experimental results for $0.08>\mathrm{C} a>0.01$. It may be observed that the droplet lengths follow a linear regression with water/oil flow-rate ratio, implying that the flow regime can also be well described by Garstecki model which was proposed for Ca number typically smaller than 0.01 (Garstecki et al., 2006). But comparing to the datapoints for $\mathrm{Ca}<0.01$ of the current study, the slope is reduced by a factor of 2 while the y-intercept remains as the same $(\delta=1 ; \epsilon=1)$. Since the channel geometry/dimension is the same for both working ranges, the difference in slope ( $\delta$ value) is mainly due to the influence of physical properties. The datapoints for $\mathrm{C} a>0.01$ were obtained by addition of $5 \%$ Butanol, so the viscosity $\mu_{0}$ and interfacial tension $\gamma_{w / 0}$ were decreased by $24 \%$ and $54 \%$ respectively compared to those of pure oil.

In the meantime, we found that the droplet lengths obtained for $0.08>\mathrm{Ca}>0.01$ were related to the capillary number $\mathrm{Ca}$ of the continuous phase, as proposed by Steegmans et al. (2009):

$\frac{L}{z}=\alpha+\beta C a^{-0.5}$

where $\alpha$ is the intercept, which in most cases turns into zero and $\beta$ is the fitting parameter in relation to mini-channel geometry/dimensions. Fig. 7 presents the lengths of plugs measured experimentally in this study for $0.08>\mathrm{Ca}>0.01$ and the fitting curve using the correlation of Steegmans et al. (2009) (Eq. (7)). It can be observed that the predicting results $(\alpha=0$, $\beta=0.32$ ) and the experimental data are generally in good agreement $(\mathrm{MAPE}=11.7 \%)$, which coincides with the constants proposed by the Steegmans model $(\alpha=0, \beta=0.334)$. On the contrary, the datapoints for $\mathrm{Ca}<0.01$ cannot be described by the shear-driven model of Steegmans et al. (2009).

Based on the above discussion, one may conclude that the droplet lengths measured in this study for $\mathrm{Ca}<0.01$ can only be predicted by Garstecki model indicating the interfacial tension force dominant squeezing regime. For $0.08>\mathrm{Ca}>0.01$, the droplets lengths can be well predicted by both Garstecki model and Steegmans model, implying the balance between interfacial tension and viscous shear stress for the droplet break-up. 

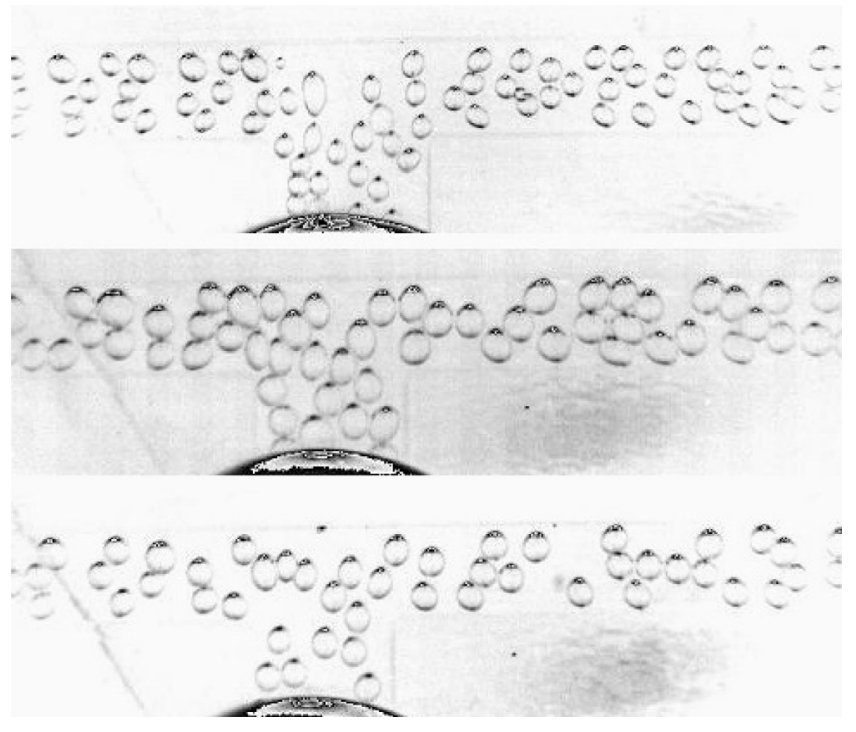

Fig. 8 - Three example images of the collected emulsion downstream of the 16 parallel Y-junctions in the minichannel device: (Top) High $P_{w}=9.99 \%$ with $0.4 \%$ SPAN, (Middle) Intermediate $P_{w}=5.81 \%$ with pure oil, (Bottom) Low $P_{w}=3.04 \%$ with pure oil.

Finally, the values of coefficient of variation $P_{w-s}$ (Eq. (1)) for emulsions produced in the single Y-junction minichannel replica are all smaller than $2.51 \%$ under both pure oil and $5 \%$ Butanol addition conditions. Nevertheless, bigger values of $P_{w-s}$ (up to $9.16 \%$ ) are observed with the addition of SPAN83 or $13 \%$ Butanol, indicating that emulsions become less homogeneous when the interfacial tension $\gamma_{w / 0}$ decreases. These results are listed in Table 5 and will be further discussed as reference case in comparison with emulsion coefficient of variation obtained in the parallel minichannel contactor.

\section{Water-oil emulsification in the parallel minichannel contactor}

Experiments on water-oil emulsification were also performed in the parallel minichannel contactor (Fig. 2) having 16 parallel identical Y-junctions. It is shown working in the video provided as supplementary material. Especially, the influences of two-phase flow properties, such as the interfacial tension $\gamma_{0 / w}$, the water and oil flow rates $Q_{w}$ and $Q_{0}$, and the oil viscosity $\mu_{0}$, on the coefficient of variation of emulsion $P_{w}$ were investigated. Fig. 8 shows three images as examples of high, intermediate and low coefficient of variation $P_{w}$ measured downstream of the 16 parallel Y-junctions. Since they are in a much larger channel section, the droplets appear as nearly spherical but distorted by shear stress. This is due to the high viscosity of the oil phase and the flow convergence at the Tjunction. Their visible black tip is actually a bright spot from the halogen light source, as the images have been inverted from their original format that can be seen, for instance in Fig. 12. The obtained experimental results are reported in Table. 5.

The capillary number $\mathrm{Ca}$ of the continuous phase is calculated at the outcome of an individual Y-junction (cross-section $0.6 \times 1 \mathrm{~mm}$, see Fig. 3a). Thus, it describes the two-phase flow patterns precisely where emulsification happens, as it does for the Y-junction replica in the previous section.

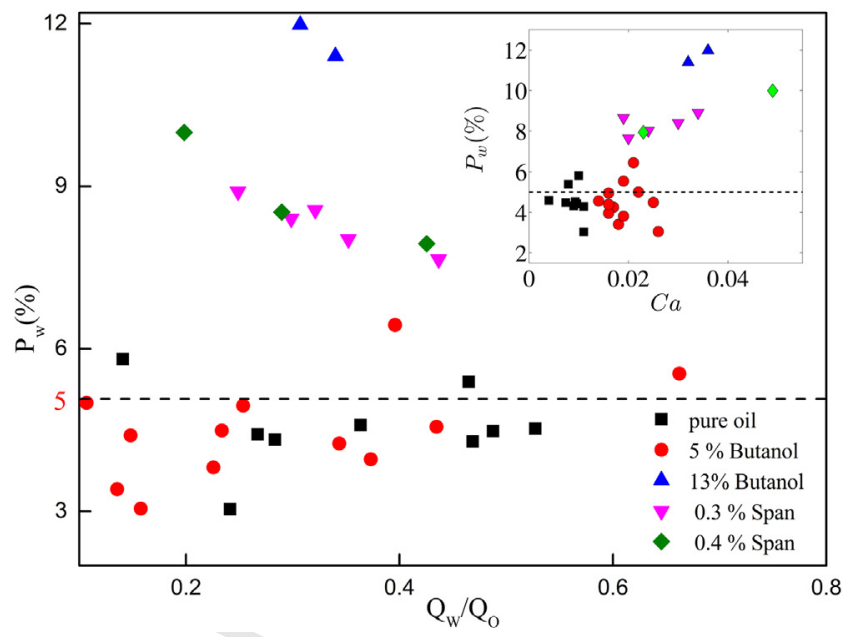

Fig. 9 - coefficient of variation $P_{w}$ as a function of water/oil flow rate ratio $Q_{w} / Q_{0}$ for various emulsions produced in the parallel minichannel contactor - Corner figure: coefficient of variation $P_{w}$ as a function of capillary number $C a$.

\subsection{Influence of parallelization on the coefficient of variation: water-pure oil emulsification}

For the case of water-pure oil emulsion, the values of $P_{w}$ are between $3.0 \%$ and $5.8 \%$ under different water/oil flow-rate ratios $\left(0.1<Q_{w} / Q_{0}<0.6\right)$. This is compared to the $P_{w-s}$ values (rightmost column in Table 5) between 1.3\%-2.51\% for the single Y-junction replica under the same working conditions. The noticeable augmentation in $P_{w}$ values is mainly due to two reasons. Firstly, the multi-scale tree-like distributor, although strictly symmetrical in geometry, could have intrinsic flow distribution non-uniformity because of the existence of elbows and the inertial forces of fluids (Fan et al., 2008; Guo et al., 2014). Regarding two-phase flow, the effect of distribution nonuniformity on the coefficient of variation of emulsion could be multiplied due to the proportion variation of fluids among the multiple channels. Secondly, each individual channel may not have the same surface roughness due to the limitation of fabrication accuracy during the manufacturing process. A small difference in minichannel geometric dimension may result in non-negligible influence on the coefficient of variation of emulsion after parallelization.

Recall that monodisperse emulsion is considered when $P_{w} \leq 5 \%$ (Xu et al., 2008; Nisisako and Torii, 2008; Nisisako et al., 2012). Hence the parallel minichannel contactor is capable of producing homogeneous water-pure oil emulsions since the values of $P_{w}$ are below or near the threshold, with the throughput multiplied by a factor of 16 owing to the parallelization.

\subsection{Influences of water and oil flow rates and} two-phase flow properties on the coefficient of variation

The effect of interfacial tension $\gamma_{w / 0}$ on the coefficient of variation of emulsion $P_{w}$ is investigated by adding SPAN 83 $\left(\rho=989 \mathrm{~kg} \mathrm{~m}^{-3}\right)$ in the oil phase, while keeping the viscosity of oil constant $\left(\mu_{0}=58 \mathrm{mPa}\right.$ ). Fig. 9 reports the coefficient of variation of emulsion as a function of water/oil flow rate ratio for three different interfacial tension cases (water-pure oil: $\gamma_{w / 0}=27.6 \mathrm{mN} \mathrm{m}^{-1}$, water-0.3\% SPAN oil: $\gamma_{w / 0}=11.7 \mathrm{mN} \mathrm{m}^{-1}$, water- $0.4 \%$ SPAN oil: $\gamma_{w / 0}=10.4 \mathrm{mN} \mathrm{m}^{-1}$ ).

It can be observed that the values of $P_{w}$ increase with the decreasing interfacial tension. When $0.3 \%$ or $0.4 \%$ wt. SPAN 83 

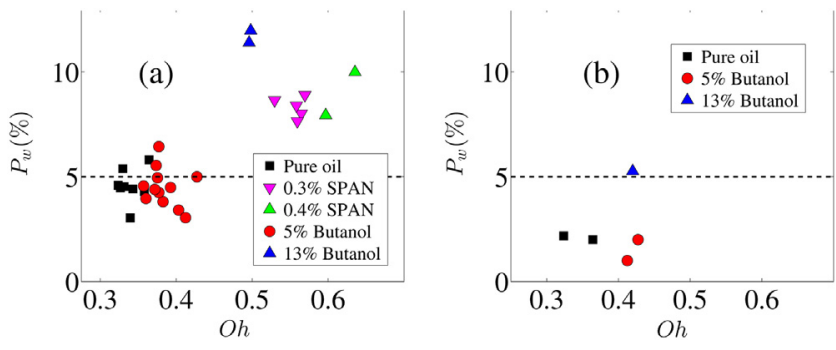

Fig. 10 - coefficient of variation $P_{w}$ as a function of Ohnesorge number Oh for various emulsions produced in the parallel minichannel contactor (a) and in the single Y-junction replica (b).

is added in the oil phase, the value of $P_{w}$ steps from $3-5 \%$ to $7-10 \%$. Although the main diameter $D_{w}$ is smaller as can be seen in Table 5 , values of $P_{w} \geq 5 \%$ indicates that the emulsion produced in the parallel minichannel contactor can no longer be considered as monodisperse.

Note that the water/oil flow-rate ratio has no significant influence on the coefficient of variation under constant interfacial tension condition, as shown in Fig. 9. In microfluidics, the effect of inertia can generally be ignored due to Reynolds numbers smaller than unity (Zhao and Middelberg, 2011). Indeed, Reynolds number is smaller than 2.5 in the present experiments.

The negative influence of $\mathrm{Ca}$ number on the coefficient of variation can also be noticed, out of the squeezing regime previously identified in the Y-junction replica for $\mathrm{Ca} \leq 0.01$. Shear stress plays a significant role for $\mathrm{C} a>0.01$. It is known as sheardriven break-up (Thorsen et al., 2001). As can be seen in the corner of Fig. 9 around the value of $\mathrm{C} a \simeq 0.02$, the $P_{w}$ value of emulsions ranges from $3 \%$ to $9 \%$. Globally, a monodisperse emulsification is obtained in the present parallel device for a capillary number Ca significantly below 0.02 to maintain the squeezing regime within the Y-junctions.

In order to further investigate the interplay between shear stress and interfacial tension, the dimensionless Ohnesorge number Oh which relates the viscous force to the inertial and interfacial tension force as defined in Eq. (4) is introduced. Fig. 10 plots the coefficient of variation of emulsion as a function of Oh for various emulsions produced in the parallel minichannel contactor (Fig. 10a) and in the single Y-junction replica (Fig. 10b). Concerning the single channel, Oh cannot be calculated in the case of a plug flow because of their noncircular shape. Thus, only 5 experiments are plotted because they produce an apparent droplet flow downstream of the Yjunction. One of them is near $5 \%$ of coefficient of variation, the others are below $2.5 \%$. In terms of monodispersity, the cost of parallelization can be seen: the gap between Fig. 10a and $\mathrm{b}$ is nearly doubled concerning low-viscosity, low-interfacial tension case with $13 \%$ butanol.

A frontier line between monodisperse and polydisperse emulsions may be clearly observed around $\mathrm{Oh}=0.45$ for parallel minichannels. This means that in order to produce a monodisperse emulsion, the viscous shear stress exerted by the surrounding flow must not exceed too much the inertia of the water droplets. As noted above, it must avoid the regime of shear-driven break-up (Thorsen et al., 2001) to achieve monodisperse emulsion. It should be noted that the critical oh number should be identical for both single minichannel and for parallel channels under ideal conditions. The departure

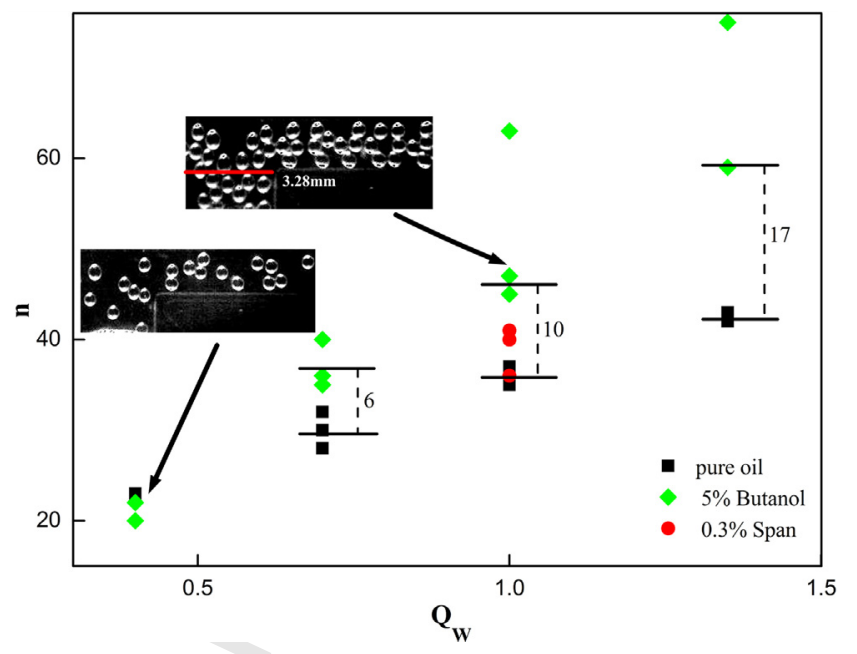

Fig. 11 - Number of droplets $n$ in the downstream area of the collector, as a function of the water flow rate $Q_{w}$ for different emulsions.

comes from the small differences/errors accumulated during the parallelization process, as already explained above.

\subsection{Influence of the water flow-rate on the number of} water droplets in emulsions

We also counted the number $n$ of water droplets presented in the principal branch of the collector (red area in the photo on Fig. 12) so as to quantify the concentration of water droplets in the emulsion. Results are listed in Table 5 and depicted in Fig. 11. It may be observed that the number $n$ rises with increasing water flow-rate $Q_{w}$. For example in water- 5 wt.\% Butanol oil emulsions, when $Q_{w}$ increases from $0.4,0.7,1.0$ to $1.35 \mathrm{~mL} \mathrm{~min}^{-1}$ with almost constant oil flow-rate $Q_{0}$, the number $n$ augments from 22, 36, 45 to 59. As a result, the water flow-rate is the primary factor influencing the number of water droplets in the produced emulsions.

It is also found that the number of droplets in two types of emulsions: water-pure oil and water-5 wt.\% Butanol oil is approximately equal at low water flow-rate $\left(Q_{w}=\right.$ $\left.0.4 \mathrm{~mL} \mathrm{~min}^{-1}\right)$. However, larger difference may be observed when $Q_{w}$ increases, as shown in Fig. 11 as indicated by the dotted lines and their magnitude. Adding 5 wt.\% Butanol in

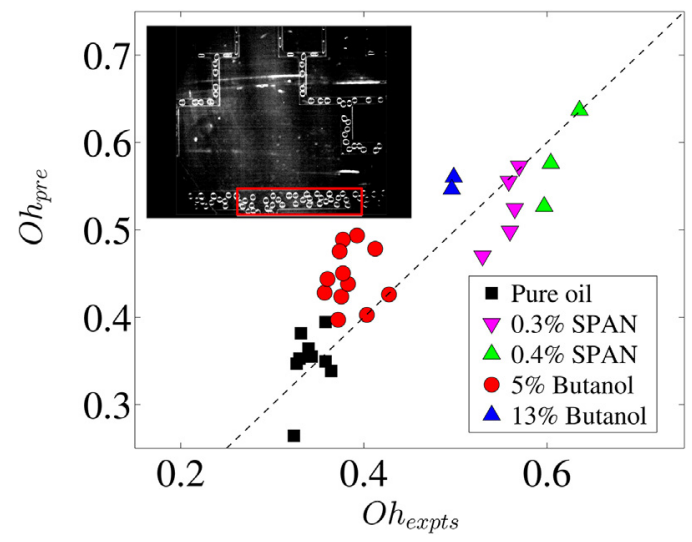

Fig. 12 - Predicted Ohnesorge number $O h_{\text {pre }}$ by Eq. (9) compared with experimental $O h_{\text {expts }}$ data in the parallel minichannel contactor - Corner photography: The red area of diameter measurement downstream the multi-scale emulsion collector. 
Table 6 - Comparison of the energy dissipation rates $E$ (Eq. (8)) for different liquid-liquid microfluidic studies.

\begin{tabular}{lccc} 
Authors & $\begin{array}{c}\text { Flow rate of emulsion } \\
\mathrm{mL} \mathrm{min}^{-1}\end{array}$ & $\begin{array}{c}\mathrm{E}(\mathrm{Eq} .(8)) \\
\mathrm{Jkg}^{-1}\end{array}$ & $D_{w}$ \\
\hline Sugiura et al. (2001) & $<10^{-2}$ & 3.5 & $20 \mu \mathrm{m}$ \\
The present study & $1.5-6.0$ & $\leq 35$ & $1 \mathrm{~mm}$ \\
Nisisako et al. (2002) & $2.5 \times 10^{-2}$ & 170 & $200 \mu \mathrm{m}$ \\
Thorsen et al. (2001) & $8 \times 10^{-4}$ & 176 & $25 \mu \mathrm{m}$ \\
Belkadi et al. (2015) & 80 & 681 & $25 \mu \mathrm{m}$ \\
\hline
\end{tabular}

the oil help to produce monodisperse emulsions with a high concentration of water droplets.

\subsection{Energy dissipation rate}

The energy dissipation rate $E$ is defined as the pumping power consumption per kg of emulsion produced (Eq. (8)).

$E=\frac{Q_{0} \quad \Delta p_{o}+Q_{w} \quad \Delta p_{w}}{\rho_{0} Q_{o}+\rho_{w} Q_{w}} \longrightarrow\left[\mathrm{J} \mathrm{kg}^{-1}\right]$

For all the experiments performed in this study, the maximum value is $43.7 \mathrm{~J} \mathrm{~kg}^{-1}$, with the maximum throughput. Similar estimations for $E$ are also performed using reported data in the literature, as shown in Table 6. It can be seen that the proposed device is capable of producing a quite high throughput of monodisperse emulsion at a relatively low energy dissipation rate, owing to the parallelization of mini-channels. However, the cited studies in Table 6 obtained droplets having 1 or 2 orders of magnitude finer sizes, implying an inevitable energy cost. Furthermore, different applications could be aimed: Belkadi et al. (2015) delivered high flow rates of emulsion $(25 \mu \mathrm{m})$ for fuel applications, whereas the present device would better suit for producing solid spherical particles with a diameter about $1 \mathrm{~mm}$.

\subsection{Fitting a predictive correlation}

Kiss et al. (2011) uses small dimensionless groups to build dimensional correlation to predict the droplet sizes. Dimensional analysis (Zlokarnik, 2006) is applied to obtain a predictive formula of $\mathrm{Oh}_{\text {pre }}$ fitting with the measured one. In the field of liquid-liquid emulsification, the viscosity ratio $\left(\frac{\mu_{0}}{\mu_{w}}\right)$ is a crucial parameter as expressed by Grace (1982). Then, the capillary number $\mathrm{Ca}$ (Zhao and Middelberg, 2011) and the water-to-oil flow rates ratio $\left(\frac{\mathrm{Q}_{w}}{\mathrm{Q}_{0}}\right)$ are also considered as great influencing factors. Finally, Eq. (9) is obtained by minimizing its gap with the present experimental results.

To evaluate the intensity of emulsification process which is affected by the liquid physical properties, the Ohnesorge number Oh compares viscous shear stress to inertia of the produced water droplets. Eq. (9) results from an optimization following the Nelder-Mead simplex method of Lagarias et al. (1998) giving the 1.64 factor and the exponents:

$O h_{\text {pre }}=1.64 \mathrm{Ca}^{0.38}\left(\frac{\mathrm{Q}_{w}}{\mathrm{Q}_{\mathrm{o}}}\right)^{0.12}\left(\frac{\mu_{\mathrm{o}}}{\mu_{w}}\right)^{0.11}$

The results show that the capillary number $\mathrm{Ca}$ has a dominant influence on the emulsification process, with the highest exponent (0.38). As explained above, the experiments with addition of Butanol and SPAN are in the "shear-driven breakup" (Thorsen et al., 2001) regime within the Y-junctions. Thus, shear stress plays a significant role in the emulsification.

The exponent of the viscosity ratio $\left(\frac{\mu_{0}}{\mu_{w}}\right)$ and the flow rates ratio $\left(\frac{\mathrm{Q}_{w}}{\mathrm{Q}_{0}}\right)$ are close, 0.11 and 0.12 , respectively. As the value of the viscosity ratio is approximate 20 times larger than the value of the flow rate ratio $(0.2 \backsim 0.6)$, the viscosity ratio is very influent to the emulsification. In this extent, Grace (1982) explained that the criterion for liquid-liquid break-up is governed by the viscosity ratio. The flow rate ratio has less influence. This is interpreted as the low influence of inertia generally stated in microfluidics (Zhao and Middelberg, 2011). The predicted value $\left(O h_{p r e}\right)$ provides a good fit with experimental values Ohexpts with a MAPE of $11 \%$, as shown in Fig. 12.

\section{Conclusion}

Water-in-oil emulsions are produced in a single Y-junction replica and in a parallel minichannel contactor. The flow regimes and the influences of the two-phase flow physical properties on the coefficient of variation of emulsion have been experimentally investigated. Based on the results and discussions presented above, the following conclusions can be drawn:

(1) For water-in-oil flows through the single Y-junction replica, an apparent droplet flow and a characterized plug flow are observed. The length of droplets/plugs can be well predicted by the correlations of Garstecki et al. (2006), and Steegmans et al. (2009) in the case of $\mathrm{Ca}>0.01$, and by both correlations of Garstecki et al. (2006) and Steegmans et al. (2009) in the case of $0.08>\mathrm{Ca}>0.01$.

(2) For water-pure oil flow, both the single Y-junction replica and the parallel minichannel contactor are capable of producing monodisperse emulsion $\left(P_{w-s}<2.51 \%, P_{w}<5.8 \%\right)$ under our tested conditions.

(3) The liquid-liquid break-up regimes and the resulting monodispersity are governed by the balance between the interfacial tension and the viscous shear stress in the continuous phase of oil. Concerning coefficient of variation $P_{w}$, the Ohnesorge number Oh which relates the viscous force to the inertial and interfacial tension force is a proper indicator. For our cases tested in this study, monodisperse emulsions could be produced in the parallel minichannel contactor when $\mathrm{Oh}<0.45$.

(4) Compared to other microfluidic emulsification devices reported in the literature, the novel parallel minichannel contactor integrated with multi-scale tree-like distributors and collector has a comparable mono-disperse emulsification performance (droplet size about $1 \mathrm{~mm}$ ) at a relatively low energy dissipation rate $\left(47 \mathrm{~J} \mathrm{~kg}^{-1}\right)$, with a relatively high throughput (1.5-6 $\left.\mathrm{mL} \mathrm{min}^{-1}\right)$.

(5) A predictive correlation for the Ohnesorge number has been derived for the parallel minichannel contactor. Its difference with the experimental data is $11 \%$.

Future investigations should enable a finer emulsification, to obtain a smaller droplet diameter. The liquid-liquid breakup has to be further investigated at the Y-junction, to minimize the pressure drop and further optimize the emulsification.

\section{Acknowledgments}

The authors gratefully acknowledge the support of China Scholarship Council (CSC). 


\section{Appendix A. Supplementary Data}

Supplementary data associated with this article can be found, in the online version, at http://dx.doi.org/10.1016/j.cherd. 2017.03.010.

\section{References}

Aarts, D., 2005. Capillary length in a fluid-fluid demixed colloid-polymer mixture. J. Phys. Chem. B 109, 7407-7411.

Belkadi, A., Tarlet, D., Montillet, A., Bellettre, J., Massoli, P., 2015. Water-in-oil emulsification in a microfluidic impinging flow at high capillary numbers. Int. J. Multiphase Flow 72, 11-23, http://www.sciencedirect.com/science/article/ pii/S0301932215000178.

Campbell, R., Martorelli, M., Lee, H., 2002. Surface roughness visualisation for rapid prototyping models. Comput. Aided Design 34, 717-725.

de Gennes, P.-G., Brochard-Wyart, F., Quéré, D., 2005. Gouttes, bulles, perles et ondes. Belin.

Duncanson, W.J., Lin, T., Abate, A.R., Seiffert, S., Shah, R.K., Weitz, D.A., 2012. Microfluidic synthesis of advanced microparticles for encapsulation and controlled release. Lab Chip 12, 2135-2145, http://dx.doi.org/10.1039/C2LC21164E.

Fan, Y., Boichot, R., Goldin, T., Luo, L., 2008. Flow distribution property of the constructal distributor and heat transfer intensification in a mini heat exchanger. AIChE J. 54, 2796-2808.

Fan, Z., Zhou, X., Luo, L., Yuan, W., 2010. Evaluation of the performance of a construcal mixer with the iodide-iodate reaction system. Chem. Eng. Process 49, 628-632.

Garstecki, P., Fuerstman, M.J., Stone, H.A., Whitesides, G.M., 2006 Formation of droplets and bubbles in a microfluidic t-junction-scaling and mechanism of break-up. Lab Chip 6 (3), $437-446$.

Grace, H., 1982. Dispersion phenomena in high viscosity immiscible fluid systems and application of static mixers as dispersion devices in such systems. Chem. Eng. Commun. 14 (1), 225-277.

Gunther, A., Jensen, K., 2006. Multiphase microfluidics: from flow characteristics to chemical and materials synthesis. Lab Chip 6, 1487-1503.

Guo, X., Fan, Y., Luo, L., 2013. Mixing performance assessment of a multi-channel mini heat exchanger reactor with arborescent distributor and collector. Chem. Eng. J. 227, 116-127, \{IMRET $\}$ 12: Proceedings of the Twelfth International Conference on Microreaction Technology. URL http://www. sciencedirect. com/science/article/pii/S1385894712011333.

Guo, X., Fan, Y., Luo, L., 2014. Multi-channel heat exchanger-reactor using arborescent distributors: a characterization study of fluid distribution, heat exchange performance and exothermic reaction. Energy 69, 728-741, http://www.sciencedirect.com/science/article/ pii/S0360544214003338.

Jeong, W.-C., Lim, J.-M., Choi, J.-H., Kim, J.-H., Lee, Y.-J., Kim, S.-H., Lee, G., Kim, J.-D., Yi, G.-R., Yang, S.-M., 2012. Controlled generation of submicron emulsion droplets via highly stable tip-streaming mode in microfluidic devices. Lab Chip 12, 1446-1453, http://dx.doi.org/10.1039/C2LC00018K.

Kandlikar, S., Grande, W., 2003. Evolution of microchannel flow passages - thermohydraulic performance and fabrication technology. Heat Transf. Eng. 24, 3-17.

Kashid, M., Gupta, A., Renken, A., Kiwi-Minsker, L., 2010. Numbering-up and mass transfer studies of liquid-liquid two-phase microstructured reactors. Chem. Eng. J. 158 (2), 233-240.

Kim, N., Murphy, M.C., Soper, S.A., Nikitopoulos, D.E., 2014. Liquid-liquid segmented flows in polycarbonate microchannels with cross-sectional expansions. Int. J. Multiphase Flow 58, 83-96.
Kiss, N., Brenn, G., Pucher, H., Wieser, J., Scheler, S., Jennewein, H., Suzzi, D., Khinast, J., 2011. Formation of O / W emulsions by static mixers for pharmaceutical applications. Chem. Eng. Sci. 66, 5084-5094.

Kobayashi, I., Uemura, K., Nakajima, M., 2007. Formulation of monodisperse emulsions using submicron-channel arrays. Colloid Surf. A: Physicochem. Eng. Aspects 296 (1-3), 285-289, http://www.sciencedirect.com/science/article/ pii/S0927775706006893.

Lagarias, J., Reeds, J.A., Wright, M.H., Wright, P.E., 1998 Convergence properties of the Nelder-mead simplex method in low dimensions. SIAM J. Optimization 9 (1), 112-147.

Li, W., Young, E.W.K., Seo, M., Nie, Z., Garstecki, P., Simmons, C.A., Kumacheva, E., 2008. Simultaneous generation of droplets with different dimensions in parallel integrated microfluidic droplet generators. Soft Matter 4, 258-262, http://dx.doi.org/10.1039/B712917C.

Link, D., Anna, S., Weitz, D., Stone, H., 2004. Geometrically mediated breakup of drops in microfluidic devices. Phys. Rev. Lett. 92 (5), 054503.

Liu, K., Ding, H., Chen, Y., Zhao, X., 2007. Droplet-based synthetic method using microflow-focusing and droplet fusion. Microfluid. Nanofluid., 239-243.

Luo, L., Fan, Y., Zhang, W., Yuan, X., Midoux, N., 2007. Integration of constructal distributors to a mini crossflow heat exchanger and their assembly configuration optimization. Chem. Eng. Sci. 62 (13), 3605-3619, frontier of Chemical Engineering Multi-scale Bridge between Reductionism and Holism. URL http://www.sciencedirect.com/science/article/ pii/S0009250907002825.

Luo, L., Fan, Z., Gall, H.L., Zhou, X., Yuan, W., 2008. Experimental study of constructal distributor for flow equidistribution in a mini crossflow heat exchanger (mche). Chem. Eng. Process.: Process Intensification 47 (2), 229-236, http://www.sciencedirect.com/science/article/ pii/S0255270107000955.

Luo, L., Tondeur, D., Gall, H.L., Corbel, S., 2007. Constructal approach and multi-scale components. Appl. Thermal Eng. 27 (10), 1708-1714, heat transfer and sustainable energy technologies. URL http://www.sciencedirect.com/science/ article/pii/S135943110600250X.

Meng, Z.-J., Wang, W., Liang, X., Zheng, W.-C., Deng, N.-N., Xie, R., Ju, X.-J., Liu, Z., Chu, L.-Y., 2015. Plug-n-play microfluidic systems from flexible assembly of glass-based flow-control modules. Lab Chip 15, 1869-1878, http://dx.doi.org/10.1039/C5LC00132C.

Moffat, R., 1988. Describing the uncertainties in experimental results. Exp. Thermal Fluid Sci. 1 (1), 3-17.

Nisisako, T., Ando, T., Hatsuzawa, T., 2012. High-volume production of single and compound emulsions in a microfluidic parallelization arrangement coupled with coaxial annular world-to-chip interfaces. Lab Chip 12 (18), 3426-3435.

Nisisako, T., Torii, T., 2008. Microfluidic large-scale integration on a chip for mass production of monodisperse droplets and particles. Lab Chip 8 (2), 287-293.

Nisisako, T., Torii, T., Higuchi, T., 2002. Droplet formation in a microchannel network. Lab Chip 2 (1), 24-26.

Priest, C., Herminghaus, S., Seemann, R., 2006. Generation of monidisperse gel emulsions in a microfluidic device. Appl. Phys. Lett. 88.

Steegmans, M.L.J., Schroën, K.G.P.H., Boom, R.M., 2009. Characterization of emulsification at flat microchannel y junctions. Langmuir 25 (6), 3396-3401, http://dx.doi.org/10.1021/la8035852, pMID: 19231876.

Sugiura, S., Nakajima, M., Iwamoto, S., Seki, M., 2001. Interfacial tension driven monodispersed droplet formation from microfabricated channel array. Langmuir 17 (1), 5562-5566.

Sugiura, S., Nakajima, M., Seki, M., 2002. Effect of channel structure on microchannel emulsification. Langmuir 18 , 5708-5712.

Tarlet, D., Mura, E., Josset, C., Bellettre, J., Allouis, C., Massoli, P., 2014. Distribution of thermal energy of child-droplets issued from an optimal micro-explosion. Int. J. Heat Mass Transfer 77 
(0), 1043-1054, http://www.sciencedirect.com/science/article/ pii/S0017931014005262.

Thorsen, T., Roberts, R., Arnold, F., Quake, S., 2001. Dynamic pattern formation in a vesicle-generating microfluidic device. Phys. Rev. Lett. 86 (1), 4163-4166.

Tice, J., Lyon, A., Ismaglov, R., 2004. Effects of viscosity on droplet formation and mixing in microfluidic channels. Anal. Chim. Acta 507, 73-77.

Tondeur, D., Fan, Y., Commenge, J.-M., Luo, L., 2011. Uniform flows in rectangular lattice networks. Chem. Eng. Sci. 66, 5301-5312.

Tondeur, D., Fan, Y., Luo, L., 2009. Constructal optimization of arborescent structures with flow singularities. Chem. Eng. Sci. 64 (18), 3968-3982, http://www.sciencedirect.com/science/ article/pii/S0009250909003686.

Tondeur, D., Luo, L., 2004. Design and scaling laws of ramified fluid distributors by the constructal approach. Chem. Eng. Sci. 59 (8-9), 1799-1813, complex Systems and Multi-scale Methodology. URL http://www.sciencedirect.com/science/ article/pii/S0009250904000934
Utada, A., Lorenceau, E., Link, D., Kaplan, P., Stone, H., Weitz, D., 2005. Monodisperse double emulsions generated from a microcapillary device. Science 308, 537-541.

Xu, J., Li, S., Tan, J., Luo, G., 2008. Correlations of droplet formation in t-junction microfluidic devices: from squeezing to dripping. Microfluid. Nanofluid. 5 (6), 711-717.

Xu, J.H., Li, S.W., Tan, J., Wang, Y.J., Luo, G.S., 2006. Preparation of highly monodisperse droplet in a t-junction microfluidic device. AIChE J. 52 (9), 3005-3010, http://dx.doi.org/10.1002/ aic.10924.

Yue, J., Boichot, R., Luo, L., Gonthier, Y., Chen, G., Yuan, Q., 2010. Flow distribution and mass transfer in a parallel microchannel contactor integrated with constructal distributor. AIChE J. 56, 298-317.

Zhao, C.-X., Middelberg, A.P.J., 2011. Two-phase microfluidic flows. Chem. Eng. Sci. 66, 1394-1411.

Zlokarnik, M., 2006. Scale-up in chemical engineering. Wiley-VCH. 